\title{
Effect of cold rolled on microstructure and mechanical properties of TiNi shape memory alloy
}

\author{
Yanfeng Li ${ }^{a}$, Xiaoyun Song ${ }^{b}$, Xiangqian Yin ${ }^{c}$ and Wenjun Ye ${ }^{d}$ \\ State Key Laboratory of Nonferrous Metals and Processes, General Institute for Non-ferrous Metals, \\ Beijing 100088, China \\ alyf@grinm.com, bsongxiaoyun@grinm.com, cyinxq@grinm.com, dwenjun_ye@grinm.com
}

Keywords: shape memory alloy, TiNi alloy, cold rolled, mechanical properties, and microstructure.

\begin{abstract}
The effect of cold rolled reductions on microstructure and mechanical properties of TiNi alloys was investigated by means of tension test and TEM. From the results it can be determined that when the annealing temperature reached $550{ }^{\circ} \mathrm{C}$, the recrystallization and grain growth began to occur after the cold deformation, and the tensile strength of the alloy decreased greatly and the elongation was more than $50 \%$. The stress platform of stress-strain curves was decided by cold deformation and anneling temperature, which meets the Clasusius-Clapeyron equation. When the alloy rolled above $37 \%$, large deformation energy storage is conducive to the occurrence of recrystallization. The microstructure evolves form recovery to nucleation of amorphous structures, recrystallization and grain growth as the rising of anealing temperature.
\end{abstract}

\section{Introduction}

TiNi shape memory alloys have been attracting much attention recently as smart materials that exhibit a transformation in crystal structure at low temperature; this allows for the metal to change shape back and forth without any damage to the microstructure. TiNi-based shape memory alloys are attractive for structural and functional applications in engineering and medicine due to their unique and important mechanical and functional properties [1-3].

Severe plastic deformation or thermomechanical treatment is necessary to improve shape memory effects and mechanical properties. Much researchers have been focused on severe plastic deformation, which can significantly influence the microstructure and phase transformation of TiNi alloys [4, 5]; in addition, the mechanical and shape memory properties are improved by forming nanostructures in the alloys. Nakayama et al. [6] found that the Ti-50.2\% Ni alloy was deformed by $50 \%$ cold rolling, the martensitic transformation did not occur during the cooling process. V.G.Pushin et al. [7] have shown that nanocrystalline microstructures are available in a large deformation, with a grain size of about tens of nanometers. In addition, the processing resulted in a greater recovery stress and maximum reverse strain of the shape memory.

The purpose of the present work is to reveal the evolution of microstructure and mechanical properties as a function of the TiNi alloy after cold rolled deformation and heat treatment.

\section{Materials and experiments}

The nominal composition of Ni50.2Ti49.8 (atom percent) alloy ingot was prepared using a high frequency induction vacuum furnace, the weight of ingot was about $20 \mathrm{~kg}$. They were then hot forging and hot rolling to the thick of $1.5 \mathrm{~mm}$. The final cold rolled at room temperature with the reduction were $12 \%, 26 \%, 37 \%, 48 \%, 58 \%$, successively. Subsequent annealing was done at 350-600 ${ }^{\circ} \mathrm{C}$ for 30 min with intervals of $50{ }^{\circ} \mathrm{C}$. The microstructural characterization of the alloys was carried out by TEM. The TEM specimens were electro-polished in an electrolyte with $90 \%$ (volume fraction) grain alcohol and $10 \%$ perchloric acid at $-40{ }^{\circ} \mathrm{C}$. The mechanical properties were investigated by tensile tests carried out on a SHIMADZU AG-250KNIS type universal tensile test machine with a strain rate of $0.5 \mathrm{~mm} / \mathrm{min}$. 


\section{Results and discussion}

Fig. 1 shows the tensile stress-strain curves of the annealed Ni50.2Ti49.8 alloys with the rolled deformation of $12 \%$ and $58 \%$, the annealing temperature was between $350{ }^{\circ} \mathrm{C}$ and $600{ }^{\circ} \mathrm{C}$. Tension test was performed at room temperature $\left(25^{\circ} \mathrm{C}\right)$.
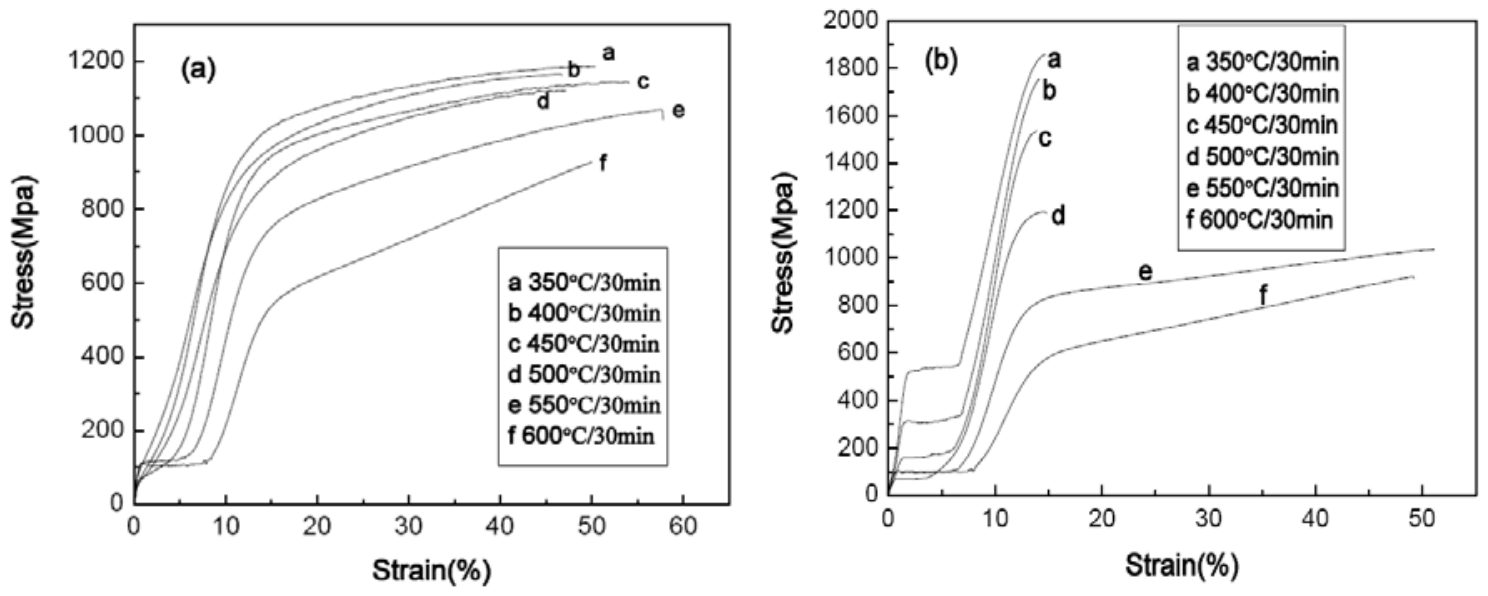

Fig.1 Stress-strain curves of Ni50.2Ti49.8 alloy with different cold rolled (a 12\%, b 58\%) after different annealing treatments

The mechanical properties of the Ni50.2Ti49.8 alloy with different cold working deformation of $12 \%, 26 \%, 37 \%, 48 \%$ and $58 \%$ after annealed at $450{ }^{\circ} \mathrm{C}, 500{ }^{\circ} \mathrm{C}, 550{ }^{\circ} \mathrm{C}$ were shown in Figure.2 (a), (b) and (c).
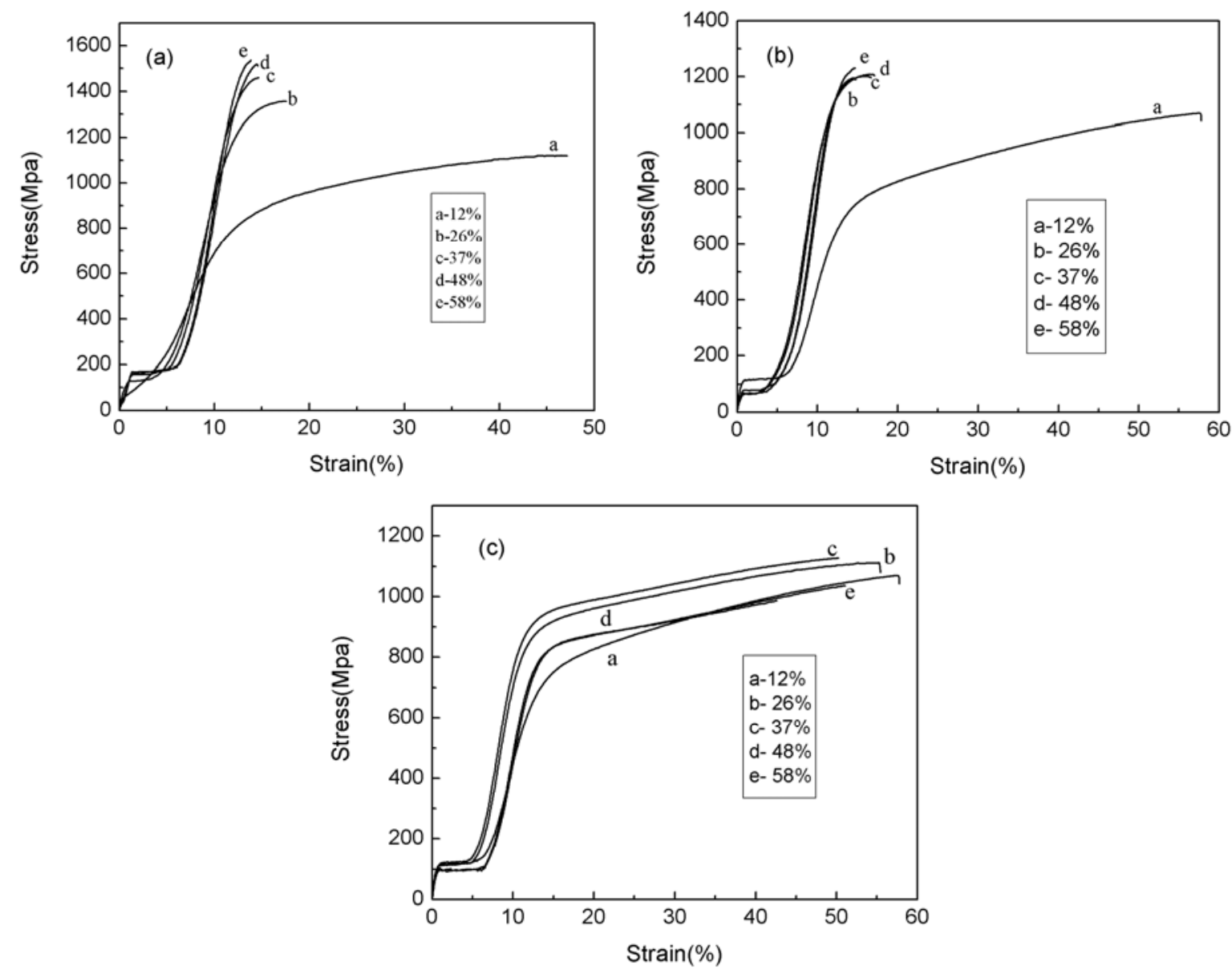

Fig.2 Stress-strain curves of Ni50.2Ti49.8 alloy with different cold rolled after different annealling treatments (annealed at $450{ }^{\circ} \mathrm{C}$ (a), annealed at $500{ }^{\circ} \mathrm{C}$ (b), annealed at $550{ }^{\circ} \mathrm{C}$ (c))

When the amount of cold rolled deformation was $12 \%$ and the annealing temperature was lower than $500{ }^{\circ} \mathrm{C}$, there was no martensite reorientation or stress-induced martensite platform on the 
stress-strain curve. The main reason was that the recrystallization of the alloy at this temperature annealing has not occurred. The lower deformation rate, the lower dislocation density, and the highly tensile strength was about 1100-1200 MPa. When the annealing temperature reached $550{ }^{\circ} \mathrm{C}$, the recrystallization occurred in the alloy, the stress strain curve appeared on the stress plateau, and the tensile strength of the alloy decreased sharply. Because of the small amount of cold working deformation, the alloy has better plasticity, and the elongation was more than $50 \%$ after annealed at different temperatures.

The mechanical properties at room temperature of $48 \%$ cold deformation and $58 \%$ cold deformation after different annealing temperature was similar, when the annealing temperature was less than $500{ }^{\circ} \mathrm{C}$, the material in a recovery or recrystallization of the initial stage, there were a large number of dislocations within the material, the elongation of the alloy was low $(<15 \%)$ and the tensile strength was high. When the annealing temperature is higher than $500{ }^{\circ} \mathrm{C}$, recrystallization and grain growth occurred in the alloy, the elongation of the alloy increase $(>50 \%)$, and the tensile strength decreased sharply.

The alloy underwent different amount of cold deformation and the same annealing temperature, the larger the cold deformation, the higher of tension strength. When the alloy was rolled the same of deformation, then annealed at different temperature, the lower the annealing temperature, the greater the strength of the alloy. When the annealing temperature reached $550{ }^{\circ} \mathrm{C}$, the recrystallization and grain growth began to occur after the cold deformation, and the tensile strength of the alloy decreased greatly and the elongation was more than $50 \%$.The stress platform of stress-strain curves was decided by cold deformation and anneling temperature, which meet the Clasusius-Clapeyron equation.
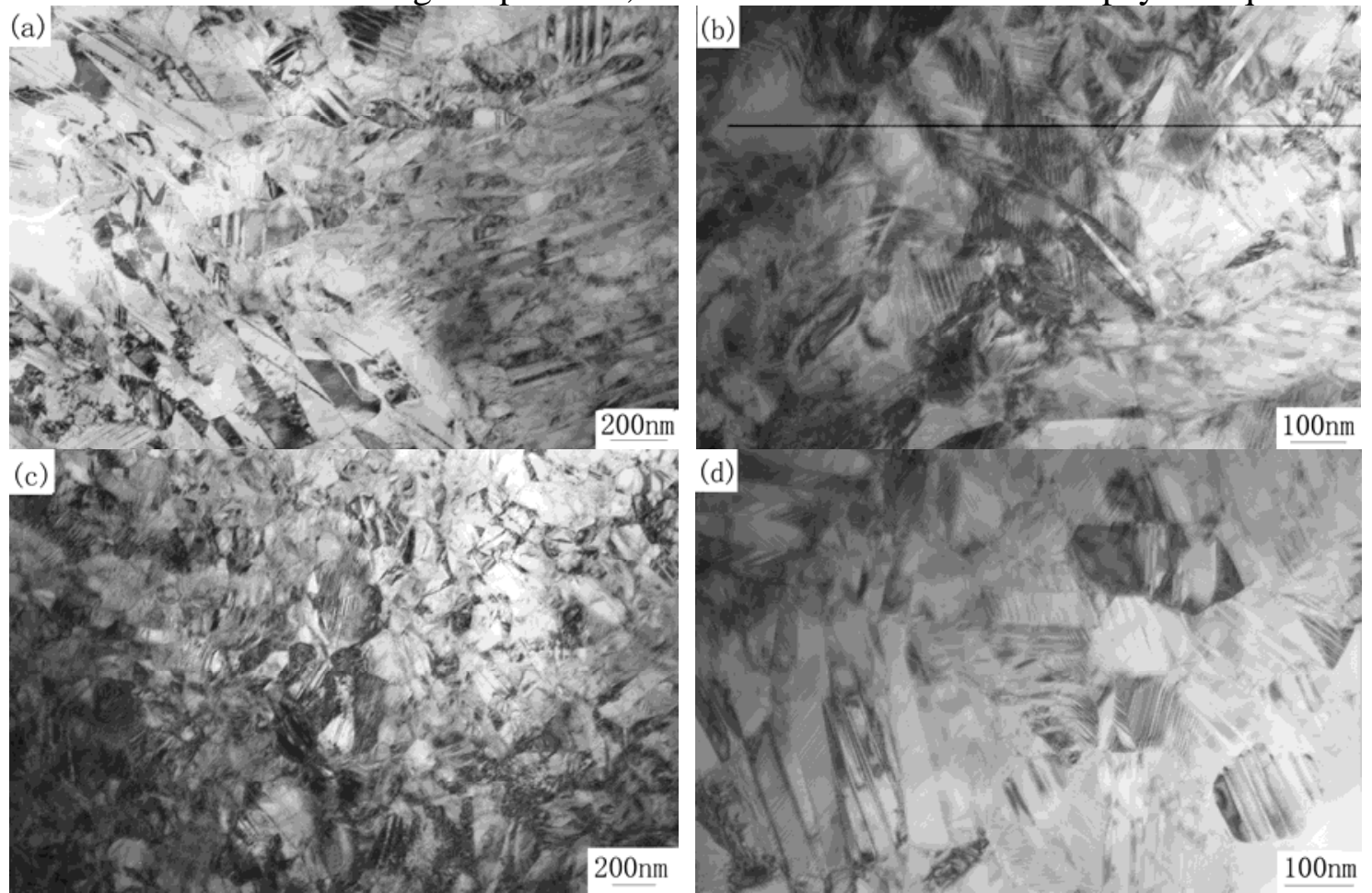

Fig.3 Microstructures of Ni50.2Ti49.8 alloy with different cold deformation (a-12\%, b-26\%, c-37\%, d-48\%) after annealed at $500{ }^{\circ} \mathrm{C}$

Microstructures of Ni50.2Ti49.8 alloy with different cold deformation after annealed at $500^{\circ} \mathrm{C}$ were shown in Figure.3. It can be seen that the alloy began to recrystallize with $12 \%$ rolling deformation and annealed at $500{ }^{\circ} \mathrm{C}$. The martensite twin became coarse when rolled by $26 \%$ deformation. When the colled deformation rised to $37 \%$, it was can be to obtaining the fine grain structure. The small grain size was about $100 \mathrm{~nm}$. When the alloy rolled with $48 \%$ and then annealed, crystallization has been completed and the grain began to grow. Therefore, it can be concluded that the higher the amount of cold working deformation, the lower the recrystallization temperature, because the processing deformation is large, the microstructure is completely broken or even obtain 
nanocrystalline, amorphous structure, and large deformation energy storage is conducive to the occurrence of recrystallization.

The results of research on effects of cold deformation on transformation and recovery properties of Ti49.8Ni50.2 alloy show that microstructure evolves as following upon the increasing of annealing temperature: recovery, forming a well-developed polygonised substructure, nucleation, recrystallization, grain growth, when deformation reduction is lower such as $12 \%$ and $26 \%$. However, microstructure evolves form recovery to nucleation of amorphous structures, recrystallization and grain growth in the case of higher deformation reduction such as $37 \%, 48 \%$ and $58 \%$.

\section{Conclusion}

The effect of cold rolled on microstructure and mechanical properties of TiNi shape memory alloy were investigated. The important conclusions are as follows:

(1) The alloy underwent different amount of cold deformation and the same annealing temperature, the larger the cold deformation, the higher of tension strength. When the annealing temperature reached $550{ }^{\circ} \mathrm{C}$, the recrystallization and grain growth began to occur after the cold deformation, and the tensile strength of the alloy decreased greatly and the elongation was more than $50 \%$.

(2) When the alloy rolled above $37 \%$ and then annealed, large deformation energy storage is conducive to the occurrence of recrystallization. The microstructure evolves form recovery to nucleation of amorphous structures, recrystallization and grain growth as the rising of anealing temperature.

\section{Acknowledgements}

This work is supported by National Natural Science Foundation of China (NSFC, No. 51571036).

\section{References}

[1]. Jan Van Humbeeck. Non-medical applications of shape memory alloys. Materials Science and Engineering A, Vol. 273-275 (1999), p.134-148.

[2]. S K Wu, H C Lin. Recent development of TiNi-based shape memory alloys in Taiwan. Materials Chemistry and Physics, Vol. 64 (2000), p. 81-92.

[3]. Kazuhiro Otsuka, Xiaobing Ren. Recent developments in the research of shape memory alloys. Intermetallics, Vol. 7 (1999), p. 511-528.

[4]. S D Prokoshkin, V Brailovski, K E Inaekyan, et al. Structure and properties of severly cold-rolled and annealed Ti-Ni shape memory alloys. Materials Science and Engineering A, Vol. 481-482 (2008), p. 114-118.

[5]. S H Chang, S K Wu, G H Chang. Transformation sequence in severely cold-rolled and annealed Ti50Ni50 alloy. Materials Science and Engineering A, Vol. 438-440 (2006), p.509-512.

[6]. H Nakayama, K Tsuchiya, M Umemoto. Crystal refinement and amorphisation by cold rolling in TiNi shape memory alloys.Scripta Materialia, Vol. 44(2001), p.1781-1785.

[7]. V G Pushin, V V Stolyarov, R Z Valiev, et al. Nanostructured TiNi-based shape memory alloys processed by severe plastic deformation. Materials Science and Engineering A, Vol. 410-411 (2005), p.386-389. 